Supporting Information

\title{
Ionic Transport and Sieving Properties of Sub-Nanoporous Polymer Membranes with Tunable Channel Size
}

Yaxiong Cheng ${ }^{1,2,3}$, Yuhua Dong ${ }^{1,2,3}$, Qinggang Huang ${ }^{1}$, Kejing Huang ${ }^{1,2,3}$, Shuangbao $\mathrm{Lyu}^{1,2,3}$, Yonghui Chen ${ }^{1,2}$, Jinglai Duan ${ }^{1,2,4,5}$, Dan $\mathrm{Mo}^{1,2,4,5}$, Youmei Sun ${ }^{1,2}$, Jie Liu ${ }^{1,2}$, Yong Peng ${ }^{3}$, and Huijun Yao ${ }^{1,2,4,5}$,

${ }^{1}$ Institute of Modern Physics, Chinese Academy of Sciences, Lanzhou 730000, P. R. China

${ }^{2}$ University of Chinese Academy of Sciences, Beijing 100049, P. R. China

${ }^{3}$ Key Laboratory for Magnetism and Magnetic Materials of Ministry of Education, Lanzhou University, Lanzhou 730000, P. R. China

${ }^{4}$ Advanced Energy Science and Technology Guangdong Laboratory, Huizhou 516000, P. R. China

${ }^{5}$ Huizhou Research Center of Ion Sciences, Huizhou 516000, P. R. China

Corresponding Author: Yaohuijun@impcas.ac.cn (H. Yao) 


\section{Channel Creation Procedure}

\subsection{Ion Irradiation Procedure}

To facilitate subsequent irradiation experiments, the purchased polycarbonate (PC) foils were cut into round piece of $5 \mathrm{~cm}$ in diameter and clamped into customized sample holder before irradiation. Membranes were then loaded into vacuum sample chamber with their surface perpendicular to the beam direction. Swift heavy ion (SHI) beam provided by HIRFL (Heavy Ion Research Facility in Lanzhou) was uniformly dispersed by two scanning magnets (including $\mathrm{X}$ and $\mathrm{Y}$ direction), and the ion fluence was monitored with a secondary electron detector. The statistical error of detector counting typically is $<5 \%$. All irradiation parameters and calculated energy loss of incident ions are summarized in Table $\mathrm{S} 1$.

Table S1. Membrane specifications and ion irradiation parameters

\begin{tabular}{|c|c|c|c|c|c|c|}
\hline \multirow{2}{*}{ Membrane } & \multirow{2}{*}{$\begin{array}{c}\text { Thickness } \\
(\mu \mathrm{m})\end{array}$} & \multirow{2}{*}{ SHI } & \multirow{2}{*}{$\begin{array}{c}\text { Ion energy } \\
(\mathrm{MeV} / \mathrm{u})\end{array}$} & \multirow{2}{*}{$\begin{array}{l}\text { Irradiation dose } \\
\qquad\left(\mathrm{cm}^{-2}\right)\end{array}$} & \multicolumn{2}{|c|}{ Energy loss $(\mathrm{keV} / \mathrm{nm})$} \\
\hline & & & & & $S_{\mathrm{e}}$ & $S_{\mathrm{n}}$ \\
\hline $\mathrm{Kr}-6 \mu \mathrm{m} \mathrm{PC}$ & 6 & ${ }^{86} \mathrm{Kr}$ & 25 & $2 \times 10^{10}$ & 2.77 & $1.32 \times 10^{-3}$ \\
\hline $\mathrm{Xe}-20 \mu \mathrm{m}$ PC & 20 & ${ }^{129} \mathrm{Xe}$ & 19.5 & $1 \times 10^{10}$ & 6.63 & $3.51 \times 10^{-3}$ \\
\hline Тa-6 $\mu \mathrm{m}$ PC & 6 & ${ }^{181} \mathrm{Ta}$ & 13.5 & $1 \times 10^{10}$ & 10.87 & $8.53 \times 10^{-3}$ \\
\hline
\end{tabular}

\subsection{UV Sensitization Procedure}

UV sensitization of PC membrane was performed after SHI irradiation, and the UV light source (MUA-165, MEJIRO GCNOSSEN, Japan) used in our experiment equipped a high-pressure mercury lamp with adjustable power and peak wavelength of $365 \mathrm{~nm}$. First, light source was needed to warm-up for 15 minutes to stabilize its output power, then a quartz culture dish containing a small amount of DI water was placed perpendicular to the UV light to filter out the infrared part in the UV light. Thereafter, adjusted the power of light source and calibrated the light intensity with an ultraviolet photometer (Model UV-A, China) at a certain distance from the light source to ensure the power being $2 \mathrm{~mW} \mathrm{~cm}^{-2}$. Finally, the membrane was placed at the same distance 
from the light source and perpendicular to the UV light. In order to ensure the homogenous UV sensitization through the whole PC membrane, both sides were sensitized one by one. The UV sensitization parameters for PC membranes are shown in Table S2. After UV sensitization, the PC membranes should be placed at least three days to stabilize the membrane structure before other treatment.

Table S2. UV sensitization parameters

\begin{tabular}{|c|c|}
\hline Irradiated membrane & UV sensitization time (h) \\
\hline Kr-6 $\mu \mathrm{m} \mathrm{PC}$ & $0,0.5,1,2,3,4,5$ and 6 \\
\hline Xe-20 $\mu \mathrm{m} \mathrm{PC}$ & $0,0.5,1,2,3,4,5$ and 6 \\
\hline Ta-6 $\mu \mathrm{m} \mathrm{PC}$ & $0,0.5,1,2$ and 3 \\
\hline
\end{tabular}

\subsection{Pulsed-Electrical Etching Procedure}

The PC membrane treated by ion irradiation and UV sensitization was sandwiched in a customized Teflon cell for electrical etching. In order to fully wet the membrane, both sides of the cell were injected with DI water to soak the membrane for $30 \mathrm{~min}$, and this operation was repeated twice. Then, the DI water was replaced with $10 \mathrm{mM} \mathrm{KCl}$ solution, and a pair of platinum electrodes were employed to impose a pulsed bias with period of $2 \mathrm{~s}$ and amplitude of $10 \mathrm{~V}$ (6482, Keithley, USA) to electrically etch the membrane. In this step, the electrical etching time was fixed to $2 \mathrm{~h}$ to avoid chemical etching of PC membrane by increased hydroxide concentration due to the prolonged water electrolysis. Besides, the ionic current tends to be saturated as etching time reaches $2 \mathrm{~h}$, which implies the relatively stable channel size in membrane at this point. After stopping electrical etching, the membrane was rinsed with DI water for three times.

\subsection{PC Nanochannel Preparation}

$6 \mu \mathrm{m}$ thick PC membrane irradiated by ${ }^{181} \mathrm{Ta}\left(13.5 \mathrm{MeV} \mathrm{u}^{-1}\right)$ with the fluence of $1 \times 10^{9}$ ions $\mathrm{cm}^{-2}$ to create nanochannels. The relatively low ion irradiation fluence aims to 
avoid nanochannel overlap. In order to obtain uniform cylindrical nanochannels in the membrane, the irradiated membrane was sensitized for $2 \mathrm{~h}$ with a UV light on each side. The membrane was then chemically etched for 1 min in $5 \mathrm{M} \mathrm{NaOH}$ solution at $50{ }^{\circ} \mathrm{C}$ with ultrasonic assistance. Finally, the etched membrane was rinsed in DI water three times to clean the residual etchant and dried in the air. The chemically etched PC membrane is shown in Figure S1a. The diameter of nanochannel in the membrane is about $16 \mathrm{~nm}$. The current-voltage $(I-V)$ curves of the nanoporous membrane exhibit the Ohmic characteristics (Figure S1b), and the corresponding conductance-voltage $\left(G^{-} V\right)$ curves are nearly horizontal (Figure S1c). The ionic conductance of the membrane is as a function of ionic hydrated diameter as shown in Figure S1d.
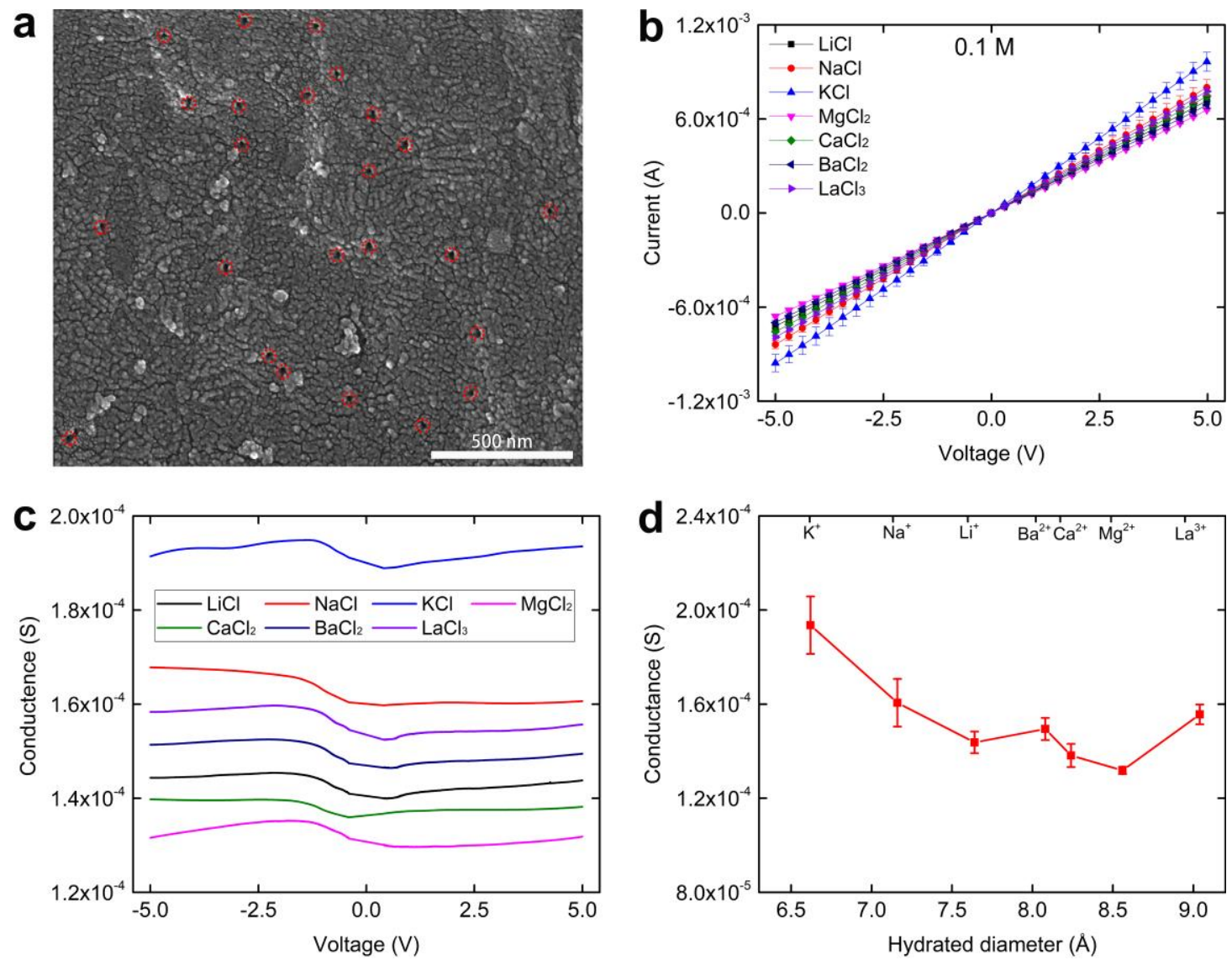

Figure S1. Morphology and ionic transport properties of the chemically etched PC membrane. (a) SEM micrograph of the membrane. The red dotted circles point out the generated nanochannels. (b) Current-voltage $(I-V)$ curves of the membrane acquired in various $0.1 \mathrm{M}$ electrolyte aqueous solutions. (c) Differential conductance-voltage $\left(G^{-} V\right)$ curves of the membrane. (d) Membrane conductance versus ionic hydrated diameter. 


\section{Measurement of Channel Size Distribution}

\subsection{Ruler-Ion Structures}

a
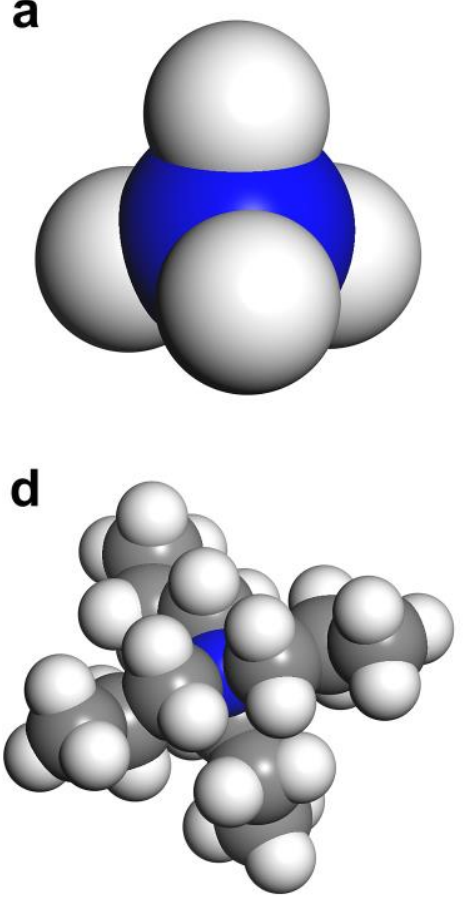

b

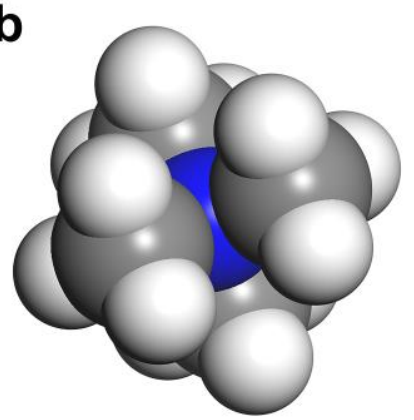

e

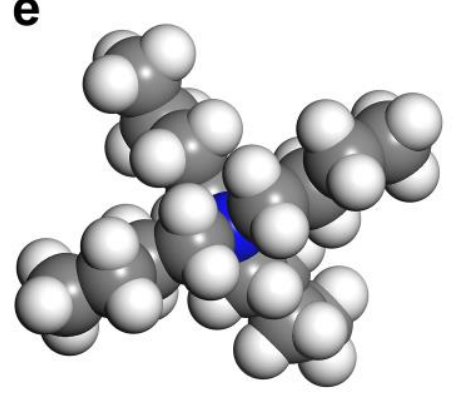

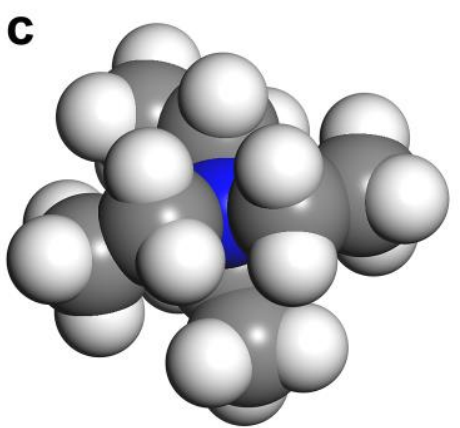

$\mathbf{f}$

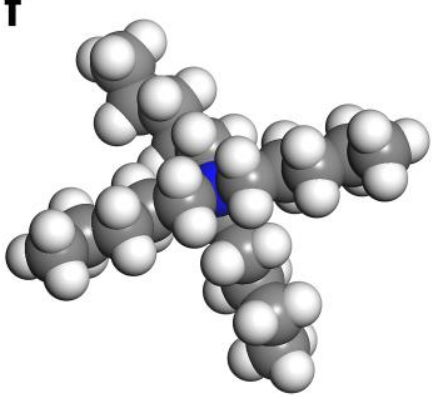

Figure S2. Schematics of ammonium ion and a series of quaternary ammonium ions. (a) Ammonium ion $\left(\mathrm{H}_{4} \mathrm{~N}^{+}\right), d=2.96 \AA$. (b) Tetramethylammonium ion $\left(\mathrm{Me}_{4} \mathrm{~N}^{+}\right), d=$ $6.94 \AA$. (c) Tetraethylammonium ion $\left(\mathrm{Et}_{4} \mathrm{~N}^{+}\right), d=8.00 \AA \AA$. (d) Tetrapropylammonium ion $\left(\operatorname{Pr}_{4} \mathrm{~N}^{+}\right), d=9.04 \AA$. (e) Tetrabutylammonium ion $\left(\mathrm{Bu}_{4} \mathrm{~N}^{+}\right), d=9.88 \AA$. (f) Tetrapentylammonium ion $\left(\mathrm{Pe}_{4} \mathrm{~N}^{+}\right), d=10.58 \AA$.

\section{Ionic Transport Property}

\subsection{Contact Angle of PC Membrane}

Figure S3 shows the aqueous contanct angle of pristine and SHIs irradiated PC membranes. The tests were performed with a contact angle meter (JGW-360A, China), and each membrane were measured at three different locations. Then, the measured results were averaged and the error ranges were calculated. The results indicate that the SHI irradiation with fluence of $10^{10}$ ions $\mathrm{cm}^{-2}$ has a minor influence on the 
hydrophobicity of PC membrane, and these membranes possess slight hydrophilicity $\left(\sim 85^{\circ}\right)$.

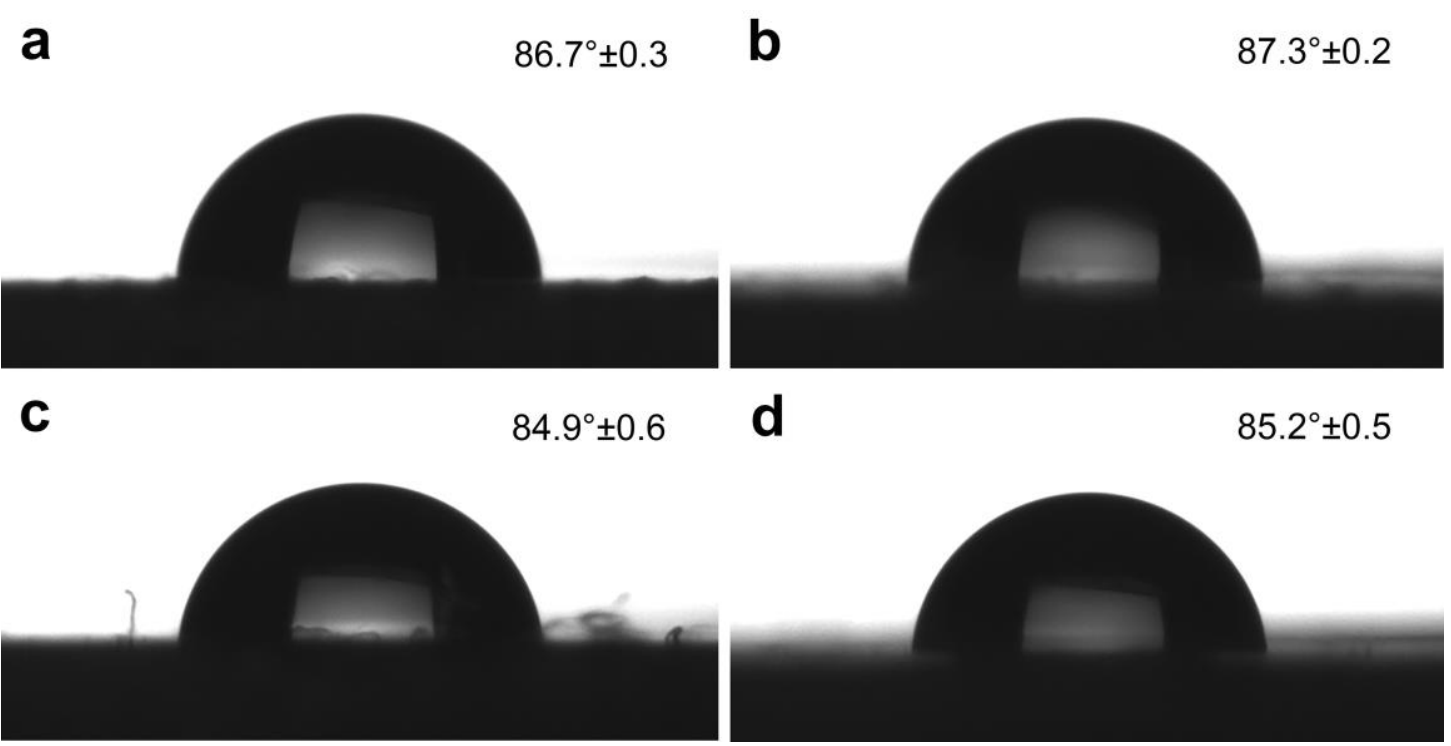

Figure S3. Aqueous contact angle of PC membranes. (a) Pristine PC membrane. (b) ${ }^{86} \mathrm{Kr}$ ion $\left(25 \mathrm{MeV} \mathrm{u}^{-1}, 2 \times 10^{10} \mathrm{~cm}^{-2}\right)$ irradiated PC membrane. (c) ${ }^{129} \mathrm{Xe}$ ion $(19.5 \mathrm{MeV}$ $\left.\mathrm{u}^{-1}, 1 \times 10^{10} \mathrm{~cm}^{-2}\right)$ irradiated PC membrane. (d) ${ }^{181} \mathrm{Ta}$ ion $\left(13.5 \mathrm{MeV} \mathrm{u}^{-1}, 1 \times 10^{10} \mathrm{~cm}^{-2}\right)$ irradiated PC membrane.

\subsection{Voltage-activated Ionic Transport}

Previous researches demonstrated that PC membrane subjected to SHI irradiation and UV sensitization can produce highly polar carboxyl and carbonyl groups on the surface $^{1-4}$, and the numerical density of functional group of membrane surface and channel wall is supposed to be equal due to the homogeneity of membrane. Therefore, the resulting channel in electrically etched membrane is negatively charged long subnanochannel (Figure S4a). Figure S4b exhibits the typical current-voltage $(I-V)$ characteristics of ionic transport in electrically etched membrane, which presents the voltage-activated nonlinear feature. It can be observed that there is a voltage gap on the curve (between $-\mathrm{V}_{1}$ and $\mathrm{V}_{1}$ ), where the ionic current is quite small and linearly increases as the voltage increases. As the voltage exceeds a threshold value $V_{1}$, ionic current significantly increases with the increase of applied voltage. Thus, we use $\gamma=$ $I / I^{\prime}$ to judge the nonlinearity degree of $I-V$ curve, where $I$ is the ionic current at $5 \mathrm{~V}$ 
voltage, $I^{\prime}$ is the calculated value from the extended line of voltage gap at $5 \mathrm{~V}$ voltage. The corresponding differential conductance-voltage $(G-V)$ curve shows the valleyshape, with a conductance gap locating in the threshold voltage range (Figure S4c). This type of voltage-activated ionic transport typically emerges in the nanofluidic systems with characteristic dimension approaching sub-nanoscale ${ }^{5-9}$. Theoretical and simulation studies have shown that the voltage-activated $I-V$ behavior can be related to hydrophobic wetting ${ }^{10}$, ionic dehydration ${ }^{11,12}$ and Coulomb blockade ${ }^{9,13,14}$. The hydrophobic wetting effect was eliminated by fully wetting our membrane in aqueous solution and choosing the stable results after multiple measurements. In addition, Coulomb blockade plays the central role in ionic transport at the high electrolyte concentration ${ }^{9}$. Therefore, ionic transport in the electrically etched membrane is mainly governed by dehydration effect at the entrance of membrane channel.

When entering the channel with the size close to the hydration diameter, hydrated ion needs to strip its hydrated shell. Thus, there is a large energy penalty to move an ion from channel exterior to its interior, while surface charge is able to reduce this energy penalty by replacing polarized waters with functional groups ${ }^{15,16}$. Such dehydration energy penalty arises an energy barrier that prevents ion from loading into channel, unless the sufficient driving force is supplied to help hydrated ion surmount the energy barrier ${ }^{11,17}$. Evidently, the energy barrier of dehydration closely relies on the relative size of hydrated ion and the channel as well as ionic hydration energy. In our experiment, the transmembrane electric field works as driving force to break hydration shell. When applied voltage is insufficient to overcome the energy barrier, ionic transport is strongly suppressed. Therefore, ionic current and conductance in membrane channels are quite small due to the small loading rate, which also causes the low ionic concentration in membrane channels (Figure S4d). Whereas the loading rate significantly increases as the applied voltage is larger than the energy barrier (Figure $\mathrm{S} 4 \mathrm{e}$ ), resulting in the higher ionic concentration in channels, as well as large ionic current and conductance. Accordingly, the threshold voltage $\left(\mathrm{V}_{1}\right)$ can qualitatively reflects the energy barrier of dehydration. 

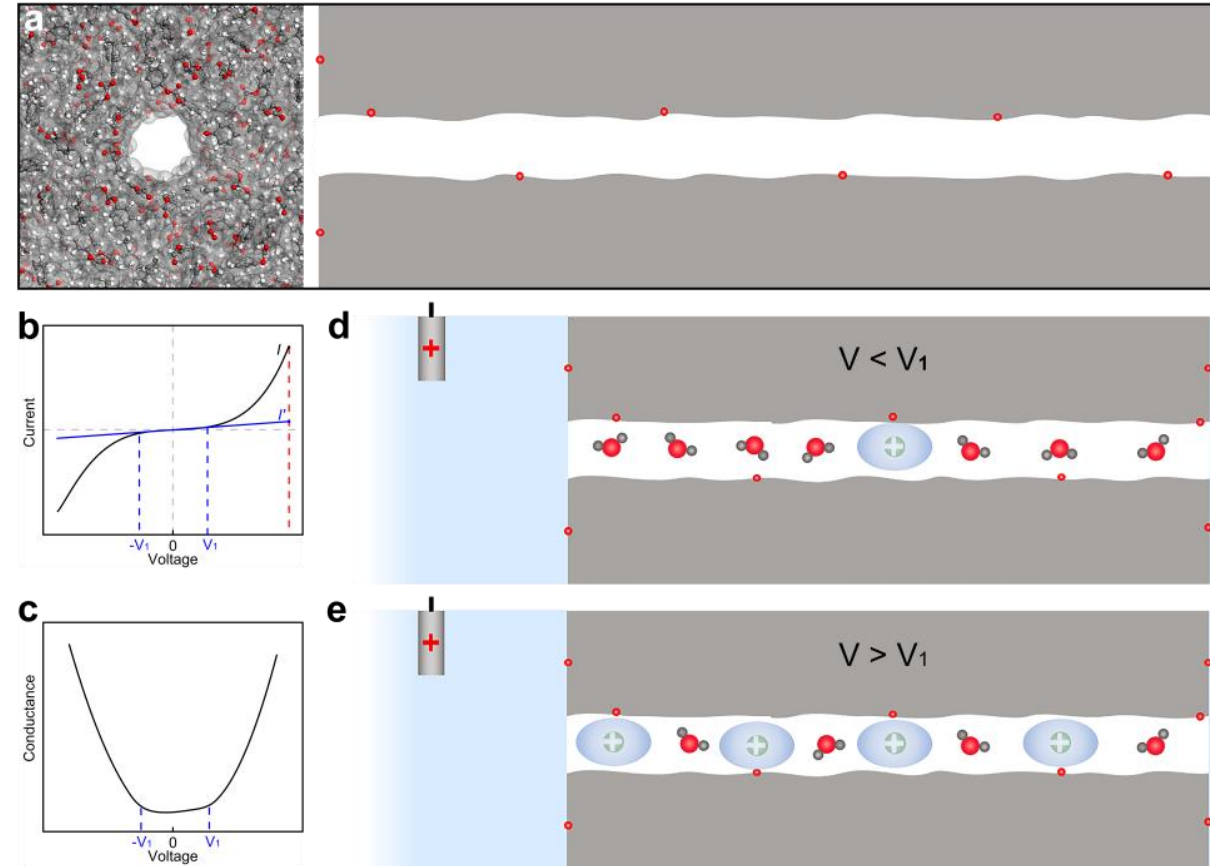

$+$

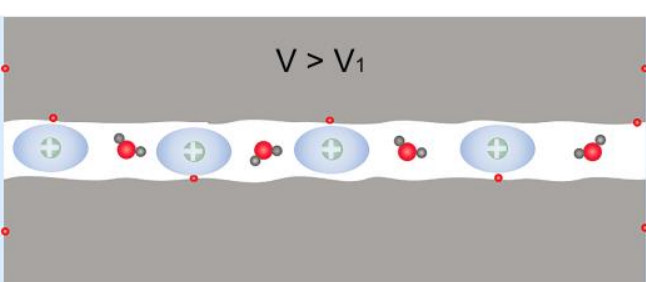

Figure S4. Voltage-activated ionic transport in electrically etched membrane. (a) The schematics of PC sub-nanochannel. The left and right panel show the channel at different views, and red dots in right panel denote the surface charges. (b) A representative voltage-activated current-voltage $(I-V)$ curve of electrically etched membrane. (c) The corresponding differential conductance-voltage $(G-V)$ curve. (d) The schematic of ionic transport in sub-nanochannel at low applied voltage. (e) The schematic of ionic transport in sub-nanochannel at high applied voltage.

\subsection{Concentration and pH Dependent Ionic Transport}
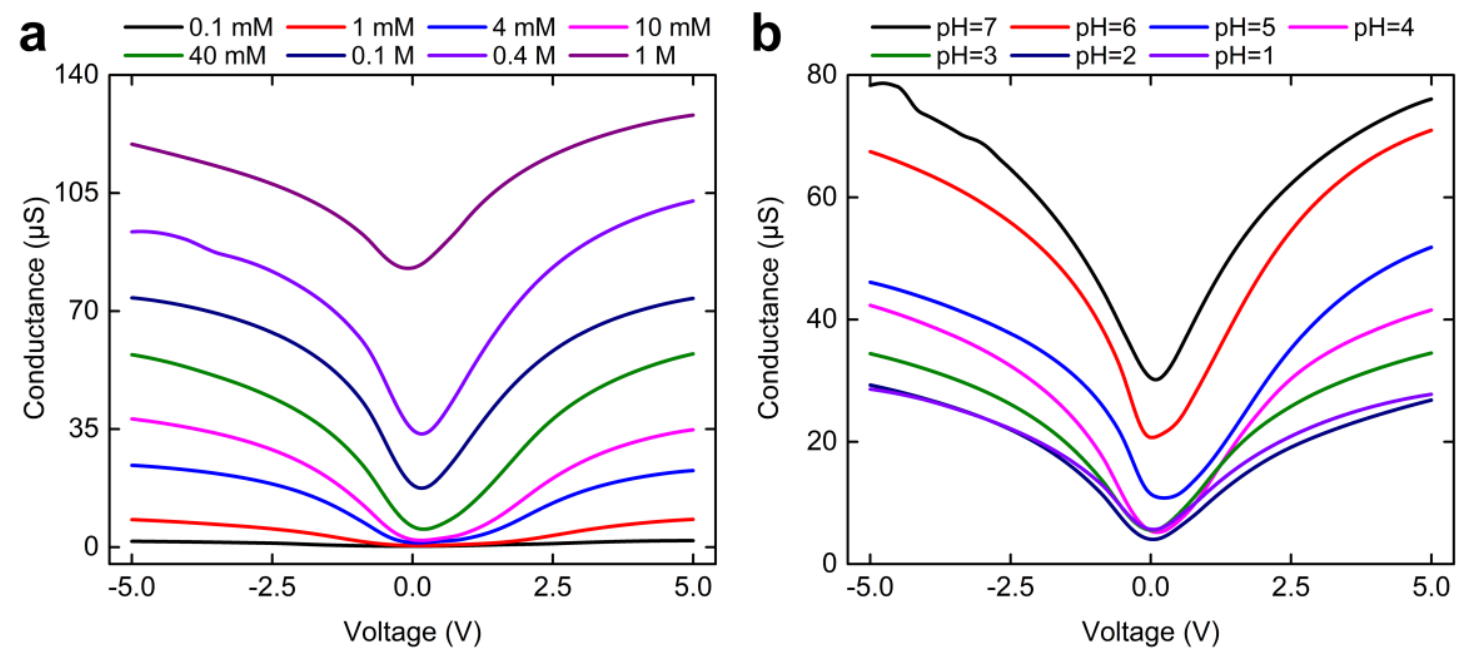

Figure S5. $G-V$ curves of an electrically etched membrane with channel mean diameter 
of $5.0 \AA$ in $\mathrm{KCl}$ aqueous solutions. (a) $G-V$ curves acquired in the $\mathrm{KCl}$ solution of different concentrations. (b) $G-V$ curves acquired in $0.1 \mathrm{M} \mathrm{KCl}$ solution with different pH conditions.
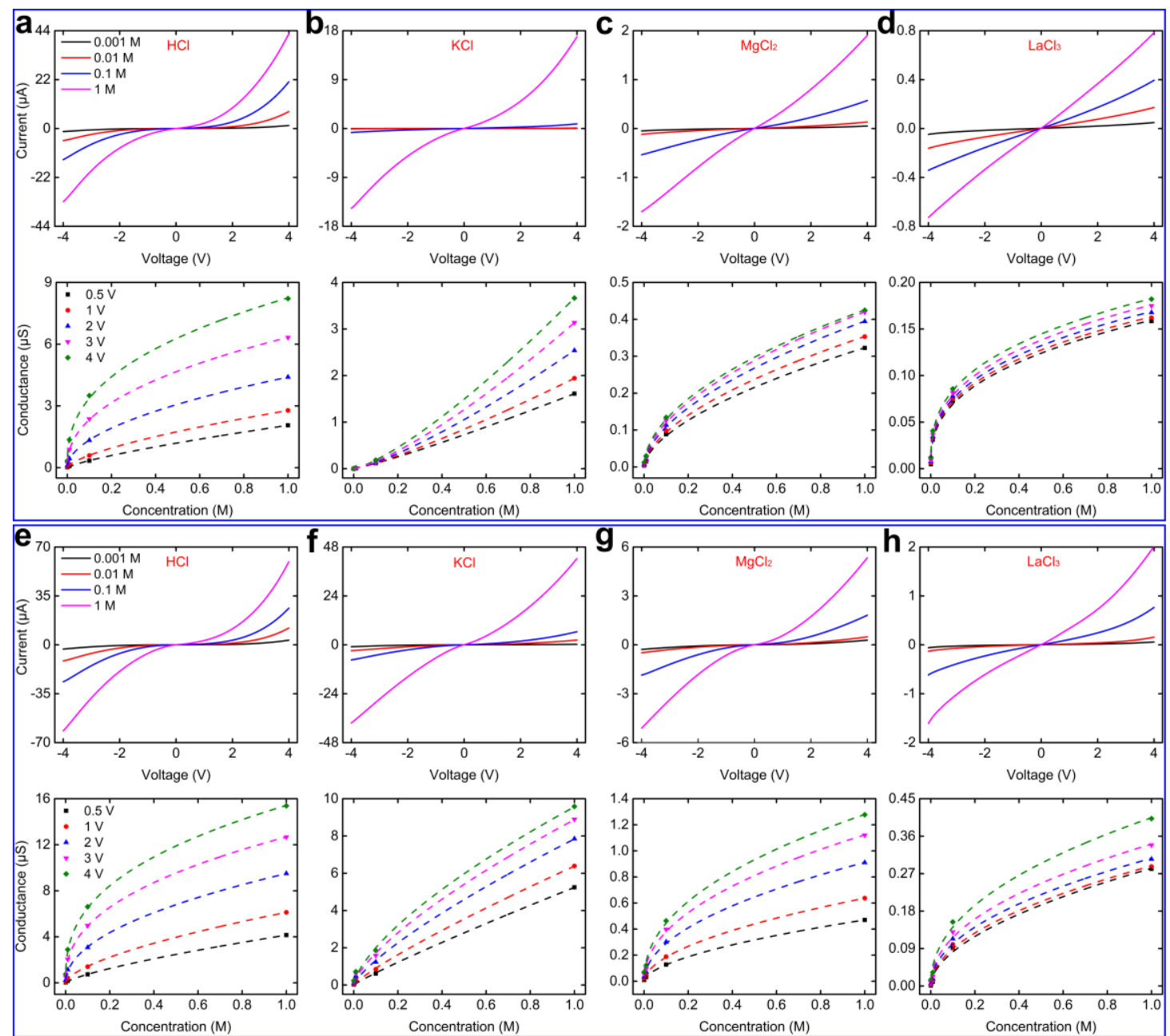

Figure S6. $I-V$ characteristics and corresponding conductance-concentration $(G-C)$ relations of an unsensitized PC membrane ( $D \approx 2.5 \AA$, top) and a 15 min UV sensitized PC membrane ( $D \approx 3.0 \AA$, bottom) in (a, e) $\mathrm{HCl}$, (b, f) $\mathrm{KCl},(\mathrm{c}, \mathrm{g}) \mathrm{MgCl}_{2}$, and (d, h) $\mathrm{LaCl}_{3}$ aqueous solutions. The dashed lines are the fitting lines on the base of the powerlaw relation $G=A \times C^{b}$. Both of the PC membranes are $6 \mu \mathrm{m}$ thick and irradiated by Ta ions with the fluence of $1 \times 10^{9}$ ions $\mathrm{cm}^{-2}$.

\subsection{Ionic Type and Channel Diameter Dependent Ionic Transport}



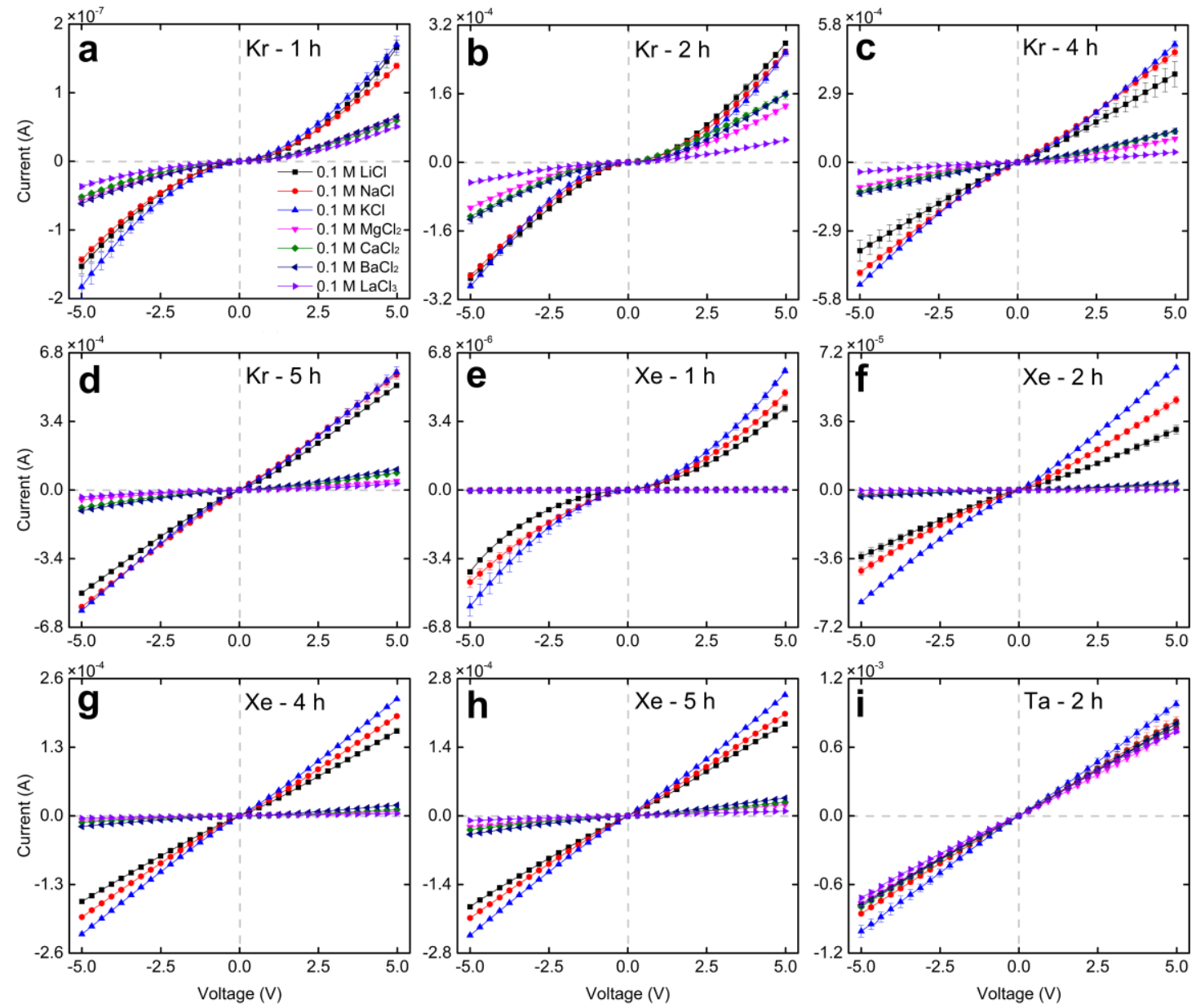

Figure S7. I- $V$ curves of electrically etched membrane acquired in different electrolyte aqueous solutions. (a-d) Kr-6 $\mu \mathrm{m}$ PC membranes with the UV sensitization time of 1 , 2, 4 and $5 \mathrm{~h}$. (e-h) Xe-20 $\mu \mathrm{m}$ PC membranes with the UV sensitization time of 1, 2, 4 and $5 \mathrm{~h}$. (i) Ta-6 $\mu \mathrm{m}$ PC membranes with the UV sensitization time of $2 \mathrm{~h}$. Measurements were conducted in $0.1 \mathrm{M} \mathrm{LiCl}, \mathrm{KCl}, \mathrm{NaCl}, \mathrm{MgCl}_{2}, \mathrm{CaCl}_{2}, \mathrm{BaCl}_{2}$ and $\mathrm{LaCl}_{3}$ aqueous solutions. 

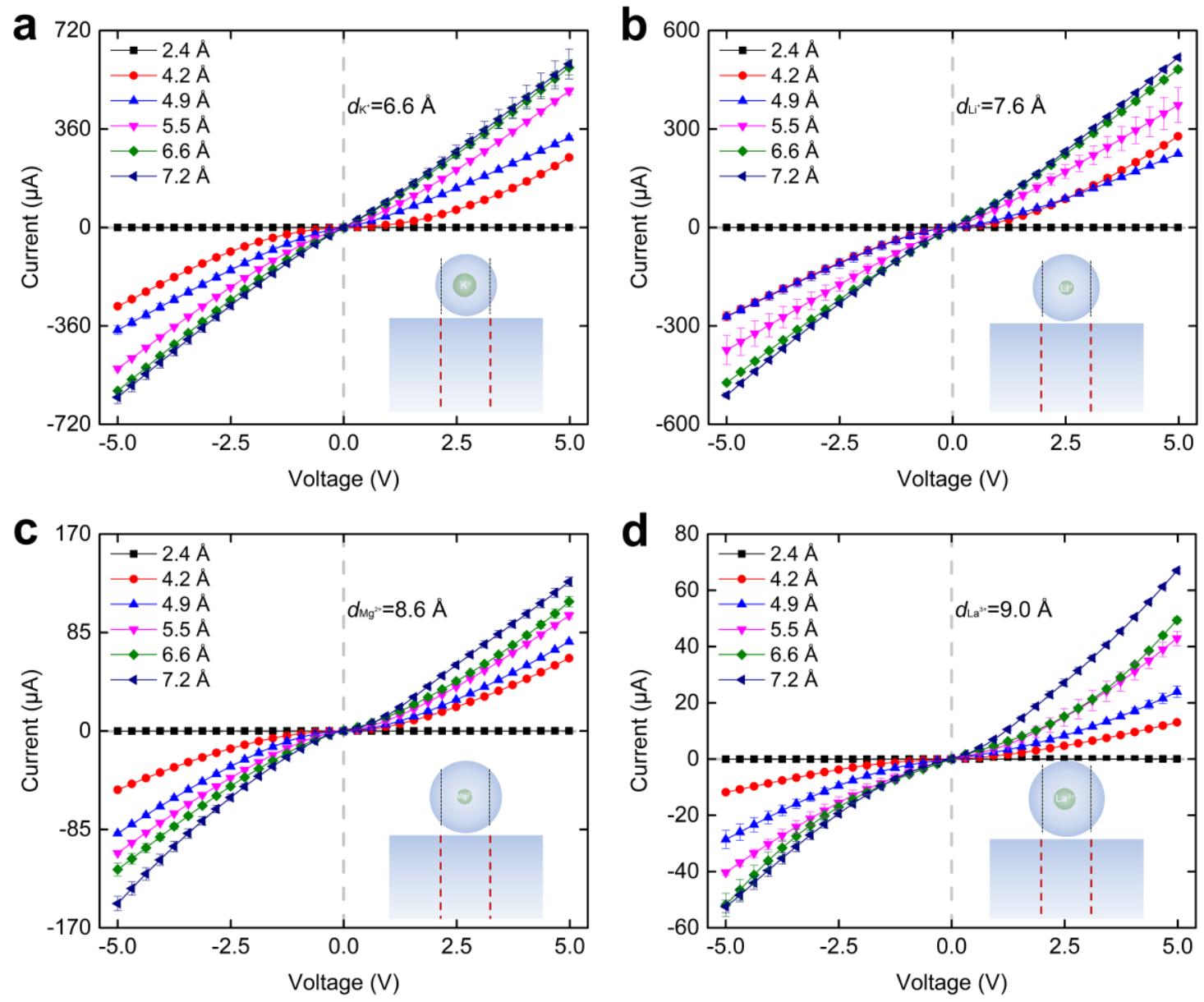

Figure S8. $I-V$ characteristics of the electrically etched membranes with different channel sizes in (a) $\mathrm{KCl}$, (b) $\mathrm{LiCl}$, (c) $\mathrm{MgCl}_{2}$, and (d) $\mathrm{LaCl}_{3}$ aqueous solution of $0.1 \mathrm{M}$ concentration. All solutions were adjusted to $\mathrm{pH} 6.5$ except for $\mathrm{LaCl}_{3}$ solution, whose $\mathrm{pH}$ was about 4.5 due to the strong hydrolysis. $d_{\mathrm{K}+}, d_{\mathrm{Li}+}, d_{\mathrm{Mg} 2+}$ and $d_{\mathrm{La} 3+}$ are the corresponding hydrated diameters for $\mathrm{K}^{+}, \mathrm{Li}^{+}, \mathrm{Mg}^{2+}$ and $\mathrm{La}^{3+}$, respectively. Insets illustrate the varying degrees of stripping for hydrated shells of different hydrated ions at the same channel mouth. 


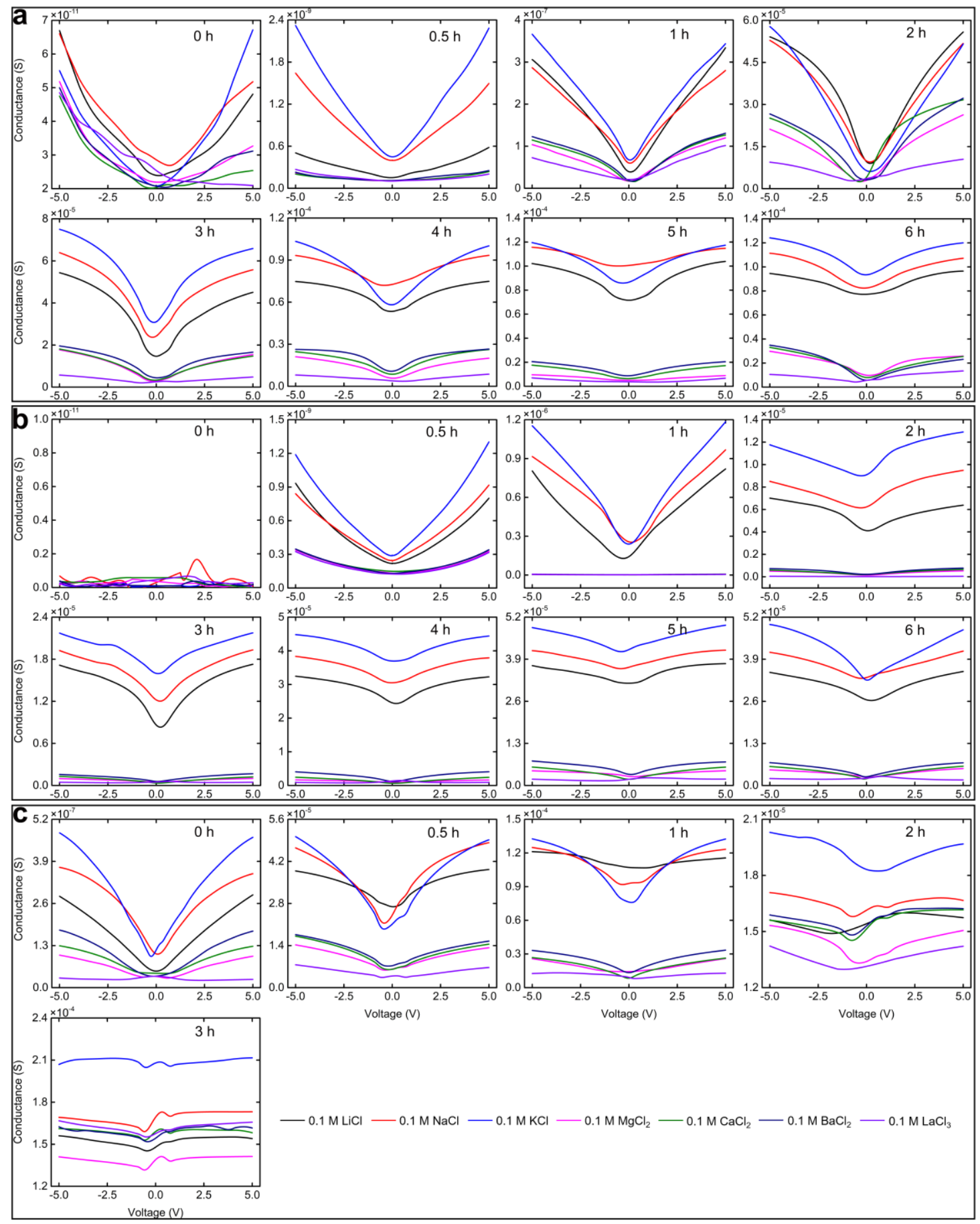

Figure S9. $G-V$ curves of electrically etched membranes in various electrolyte aqueous solutions. (a-d) Kr-6 $\mu$ m PC membranes with UV sensitization time from 0 to $6 \mathrm{~h}$. (e-h) Xe-20 $\mu \mathrm{m}$ PC membranes with UV sensitization time from 0 to 6 h. (i) Ta- $6 \mu \mathrm{m}$ PC membrane with UV sensitization time from 0 to $3 \mathrm{~h}$.

\section{Ionic Diameter and Hydration Energy}


Table S3. The diameter and hydration energy of different ions

\begin{tabular}{|c|c|c|c|}
\hline Ion & $\begin{array}{c}\text { Bare diameter } \\
(\AA)\end{array}$ & $\begin{array}{c}\text { Hydrated diameter } \\
(\AA)\end{array}$ & $\begin{array}{c}\text { Hydration energy }^{19} \\
\left(-\mathrm{kJ} \mathrm{mol}^{-1}\right)\end{array}$ \\
\hline $\mathrm{H}_{3} \mathrm{O}^{+}$ & 2.3 & 5.64 & - \\
\hline $\mathrm{Li}^{+}$ & 1.2 & 7.64 & 375 \\
\hline $\mathrm{Na}^{+}$ & 1.9 & 7.16 & 295 \\
\hline $\mathrm{K}^{+}$ & 2.66 & 6.62 & 1830 \\
\hline $\mathrm{Mg}^{2+}$ & 1.3 & 8.56 & 1505 \\
\hline $\mathrm{Ca}^{2+}$ & 1.98 & 8.24 & 1250 \\
\hline $\mathrm{Ba}^{2+}$ & 2.846 & 8.08 & 3145 \\
\hline $\mathrm{La}^{3+}$ & 2.3 & 9.04 & 340 \\
\hline $\mathrm{Cl}^{-}$ & 3.62 & 6.64 & 430 \\
\hline $\mathrm{OH}^{-}$ & 3.52 & 6.00 & 285 \\
\hline $\mathrm{H}_{4} \mathrm{~N}^{+}$ & 2.96 & 6.62 & 160 \\
\hline $\mathrm{Me}_{4} \mathrm{~N}^{+}$ & 6.94 & 7.34 & 0 \\
\hline $\mathrm{Et}_{4} \mathrm{~N}^{+}$ & 8.00 & 8.00 & 0 \\
\hline $\mathrm{Pr}_{4} \mathrm{~N}^{+}$ & 9.04 & 9.04 & 0.88 \\
\hline $\mathrm{Bu}_{4} \mathrm{~N}^{+}$ & 9.88 & 9.88 & 0 \\
\hline $\mathrm{Pe}_{4} \mathrm{~N}^{+}$ & 10.58 & & 0 \\
\hline
\end{tabular}

\section{References}

1. Lemaire, J.; Gardette, J.-L.; Rivaton, A.; Roger, A., Dual photo-chemistries in aliphatic polyamides, bisphenol A polycarbonate and aromatic polyurethanes-A short review. Polym. Degrad. Stab. 1986, 15, 1-13.

2. Ferain, E.; Legras, R., Heavy-ion tracks in polycarbonate. Radiat. EIT. 1993, 126, 243-246.

3. Hareesh, K.; Sanjeev, G.; Pandey, A. K.; Rao, V., Characterization of UV-irradiated Lexan polycarbonate films. Iran. Polym. J. 2013, 22, 341-349. 
4. Fink, D., Fundamentals of Ion-Irradiated Polymers. Springer: 2004; Vol. 63, p 174.

5. Chung, S. H.; Kuyucak, S., Recent advances in ion channel research. Biochim. Biophys. Acta 2002, 1565, 267-286.

6. Liu, L.; Yang, C.; Zhao, K.; Li, J.; Wu, H.-C., Ultrashort single-walled carbon nanotubes in a lipid bilayer as a new nanopore sensor. Nat. Commun. 2013, 4, 2989.

7. Jain, T.; Rasera, B. C.; Guerrero, R. J. S.; Boutilier, M. S. H.; O'Hern, S. C.; Idrobo, J.-C.; Karnik, R., Heterogeneous sub-continuum ionic transport in statistically isolated graphene nanopores. Nat. Nanotechnol. 2015, 10, 1053-1057.

8. Wen, Q.; Yan, D.; Liu, F.; Wang, M.; Ling, Y.; Wang, P.; Kluth, P.; Schauries, D.; Trautmann, C.; Apel, P.; Guo, W.; Xiao, G.; Liu, J.; Xue, J.; Wang, Y., Highly Selective Ionic Transport through Subnanometer Pores in Polymer Films. Adv. Funct. Mater. 2016, 26, 5796-5803.

9. Feng, J.; Liu, K.; Graf, M.; Dumcenco, D.; Kis, A.; Di Ventra, M.; Radenovic, A., Observation of ionic Coulomb blockade in nanopores. Nat. Mater. 2016, 15, 850-855. 10. Powell, M. R.; Cleary, L.; Davenport, M.; Shea, K. J.; Siwy, Z. S., Electric-fieldinduced wetting and dewetting in single hydrophobic nanopores. Nat. Nanotechnol. 2011, 6, 798-802.

11. Richards, L.; Schaefer, A.; Richards, B.; Corry, B., The Importance of Dehydration in Determining Ion Transport in Narrow Pores. Small 2012, 8, 1701-9.

12. Sahu, S.; Di Ventra, M.; Zwolak, M., Dehydration as a Universal Mechanism for Ion Selectivity in Graphene and Other Atomically Thin Pores. Nano Lett. 2016, 17.

13. Li, W.; Wang, W.; Zhang, Y.; Yan, Y.; Dai, C.; Zhang, J., Gated Water Transport Through Graphene Nanochannels: From Ionic Coulomb Blockade to Electroosmotic Pump. The Journal of Physical Chemistry C 2017, 121.

14. Nikita; Kavokine; Sophie; Marbach; Alessandro; Siria; Lydéric; Bocquet, Ionic Coulomb blockade as a fractional Wien effect. Nat. Nanotechnol. 2019, 14, 573-578. 15. Zwolak, M.; Lagerqvist, J.; Di Ventra, M., Quantized ionic conductance in nanopores. Phys. Rev. Lett. 2009, 103.

16. Bostick, D.; Brooks, C., Selectivity in $\mathrm{K}+$ channels is due to topological control of the permeant ion's coordinated state. Proc. Natl. Acad. Sci. U.S.A. 2007, 104, 9260-5. 
17. Thomas, M.; Corry, B.; Hilder, T., What Have We Learnt About the Mechanisms of Rapid Water Transport, Ion Rejection and Selectivity in Nanopores from Molecular Simulation? Small 2014, 10, 1453-1465.

18. Nightingale, E., Phenomenological Theory of Ion Solvation. Effective Radii of Hydrated Ions. J. Phys. Chem. 1958, 63, 566-567.

19. Marcus, Y., A simple empirical model describing the thermodynamics of hydration of ions of widely varying charges, sizes, and shapes. Biophys. Chem. 1994, 51, 111-127. 